\title{
Arcanobacterium pluranimalium sp. nov., isolated from porpoise and deer
}

\author{
Paul A. Lawson, ${ }^{1}$ Enevold Falsen, ${ }^{2}$ Geoffrey Foster, ${ }^{3}$ Erik Eriksson, ${ }^{4}$ \\ Norbert Weiss ${ }^{5}$ and Matthew D. Collins ${ }^{1}$
}

Author for correspondence: Matthew D. Collins. Tel: +44 118935 7226. Fax: +44 1189357222. e-mail: m.d.collins@reading.ac.uk

\author{
1 Department of Food \\ Science and Technology, \\ University of Reading, \\ Whiteknights, PO Box 226, \\ Reading RG6 6AP, UK \\ 2 Culture Collection, \\ Department of Clinical \\ Bacteriology, University of \\ Göteborg, Göteborg, \\ Sweden \\ 3 SAC Veterinary Service \\ Division, Inverness, UK \\ ${ }^{4}$ National Veterinary \\ Institute, Uppsala, Sweden \\ 5 Deutsche Sammlung von \\ Mikroorganismen und \\ Zellkulturen $\mathrm{GmbH}$, \\ Braunschweig, Germany
}

\begin{abstract}
Two strains of a previously undescribed Arcanobacterium-like bacterium were isolated from a dead harbour porpoise and a dead sallow deer. Biochemical testing and PAGE analysis of whole-cell proteins indicated that the strains were phenotypically closely related to each other and distinct from previously described Actinomyces and Arcanobacterium species. Comparative 16S rRNA gene sequencing studies showed the bacterium to be a hitherto unknown subline within the genus Arcanobacterium. Based on phylogenetic and phenotypic evidence, it is proposed that the unknown bacterium be classified as Arcanobacterium pluranimalium sp. nov. The type strain of Arcanobacterium pluranimalium is CCUG 42575' (= CIP 106442 ${ }^{\top}$ ).
\end{abstract}

Keywords: taxonomy, phylogeny, Arcanobacterium pluranimalium, 16S rRNA

\section{INTRODUCTION}

The genus Arcanobacterium (Collins et al., 1982) was created to accommodate the species formerly designated Corynebacterium haemolyticum. Initially, the genus consisted of the single species Arcanobacterium haemolyticum. However, recent phylogenetic studies have resulted in the reclassification of Actinomyces bernardiae and Actinomyces pyogenes as Arcanobacterium bernardiae and Arcanobacterium pyogenes, respectively (Pascual et al., 1997). In addition, a fourth member of the genus, Arcanobacterium phocae, isolated from seals, has been described (Pascual et al., 1997). The aforementioned Arcanobacterium species have all been recovered from human and/or animal sources and some are recognized pathogens. Arcanobacterium haemolyticum is associated primarily with pharyngitis and with mixed wound infections, whereas Arcanobacterium bernardiae has been recovered from a variety of human clinical specimens (e.g. abscesses, blood; see Funke et al., 1995). Arcanobacterium pyogenes is a well-established cause of pyogenic infections in animals and is also known to cause human disease, albeit rarely (Funke et al., 1995). Arcano-

The GenBank accession number for the 16S rRNA gene sequence of strain CCUG $42575^{\top}$ is AJ250959. bacterium phocae has been isolated from seals but is of unknown pathological significance (Pascual et al., 1997). During the course of a study of taxonomically problematic Actinobacteria from wild animals, two Arcanobacterium-like organisms, one from a dead harbour seal and the second from a dead sallow deer, were characterized. Based on the results of a polyphasic taxonomic study, yet another new species of the genus Arcanobacterium, Arcanobacterium pluranimalium, is described.

\section{METHODS}

Strains. Strain M430/94/2 $\left(=\right.$ CCUG $42575^{\mathrm{T}}$ ) was isolated from the spleen of a dead harbour porpoise. Strain CCUG 41729 was recovered from a lung abscess of a dead sallow deer. The unidentified Arcanobacterium-like isolates were cultivated on Columbia agar (Difco) supplemented with $5 \%$ horse blood at $37^{\circ} \mathrm{C}$, in air plus $5 \% \mathrm{CO}_{2}$.

Phenotypic characterization. The strains were biochemically characterized by using the API rapid ID32 Strep and API CORYNE systems according to the manufacturer's instructions (API bioMérieux). The type strains and other reference strains used in the investigation were all maintained by the Culture Collection of the University of Göteborg, Sweden. All tests were performed in duplicate.

SDS-PAGE of whole-cell protein. To assess the phenotypic resemblance of the two isolates to each other and to reference 


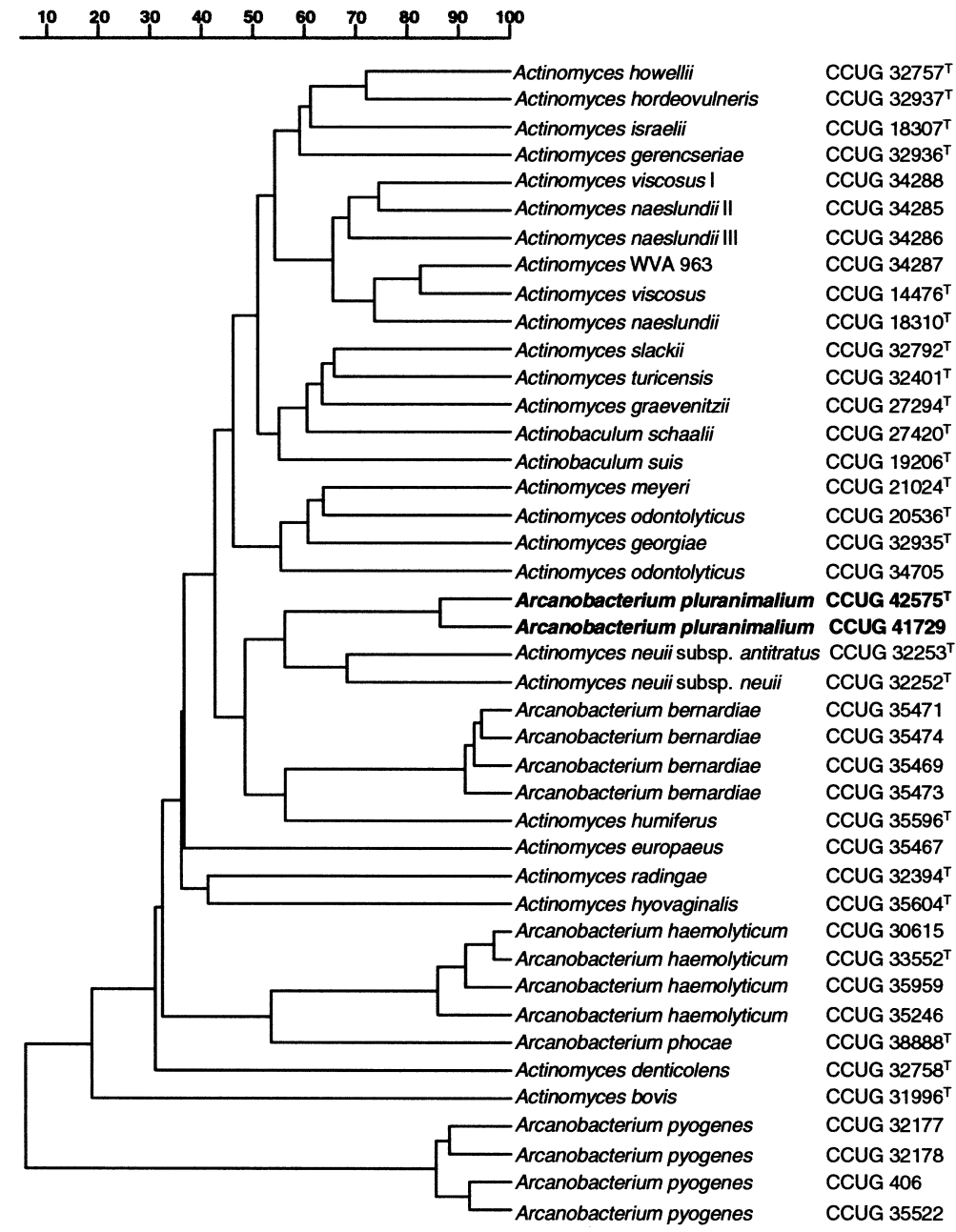

Fig. 1. Similarity dendrogram based on whole-cell protein patterns of Arcanobacterium pluranimalium sp. nov. and related species. Levels of correlation are expressed as percentages of similarity for convenience.

Arcanobacterium species, a comparative analysis of wholecell protein profiles by SDS-PAGE was performed. PAGE analysis of whole-cell proteins was performed as described previously (Pot et al., 1994; Vandamme et al., 1998). For densitometric analysis, normalization and interpretation of protein patterns, the GCW 3.0 software package (Applied Maths, Kortrijk, Belgium) was used. The similarity between all pairs of traces was expressed by the Pearson productmoment correlation coefficient converted for convenience to percentage similarity.

Phylogenetic analysis. The $16 \mathrm{~S}$ rRNA genes of the two isolates were amplified by PCR and directly sequenced using a Taq dideoxy terminator cycle sequencing kit (Applied Biosystems) and an automatic DNA sequencer (model 373A; Applied Biosystems). The closest known relatives of the new isolates were determined by performing database searches. These sequences and those of other known related strains were retrieved from the GenBank or Ribosomal Database Project (RDP) databases and aligned with the newly determined sequences using the program PILEUP (Devereux et al., 1984). The resulting multiple sequence alignment was corrected manually and a distance matrix was calculated using the programs PRETTY and DNADIST (using the Kimura two-correction parameter) (Felsenstein, 1989). A phylogenetic tree was constructed according to the neighbour-joining method with the program NEIGHBOR
(Felsenstein, 1989). The stability of the groupings was estimated by bootstrap analysis (500 replications) using the programs SEQBOOT, DNADIST, NEIGHBOR and CONSENSE (Felsenstein, 1989).

\section{RESULTS AND DISCUSSION}

The two isolates consisted of Gram-positive, straight to slightly curved, non-branching, slender rods which were non-acid-fast and non-spore-forming. The strains were catalase-positive and $\alpha$-haemolytic on blood agar. Phenotypically, they closely resembled each other producing acid from D-glucose and D-ribose. Neither strain produced acid from D-arabitol, L-arabinose, cyclodextrin, glycogen, pullulan, sorbitol, mannitol, melibiose, melezitose, lactose, D-raffinose, sucrose, tagatose, trehalose or D-xylose. Results for acid production from maltose differed between the different API systems employed. Using the API CORYNE kit, acid was produced with this substrate. However, with the API rapid ID32 Strep system, this substrate was not fermented. Both isolates gave positive reactions for alanine phenylalanine proline arylamidase, pyroglutamic acid arylamidase and $\beta$-glucuronidase, but they were negative for arginine dihydrolase, alkaline 


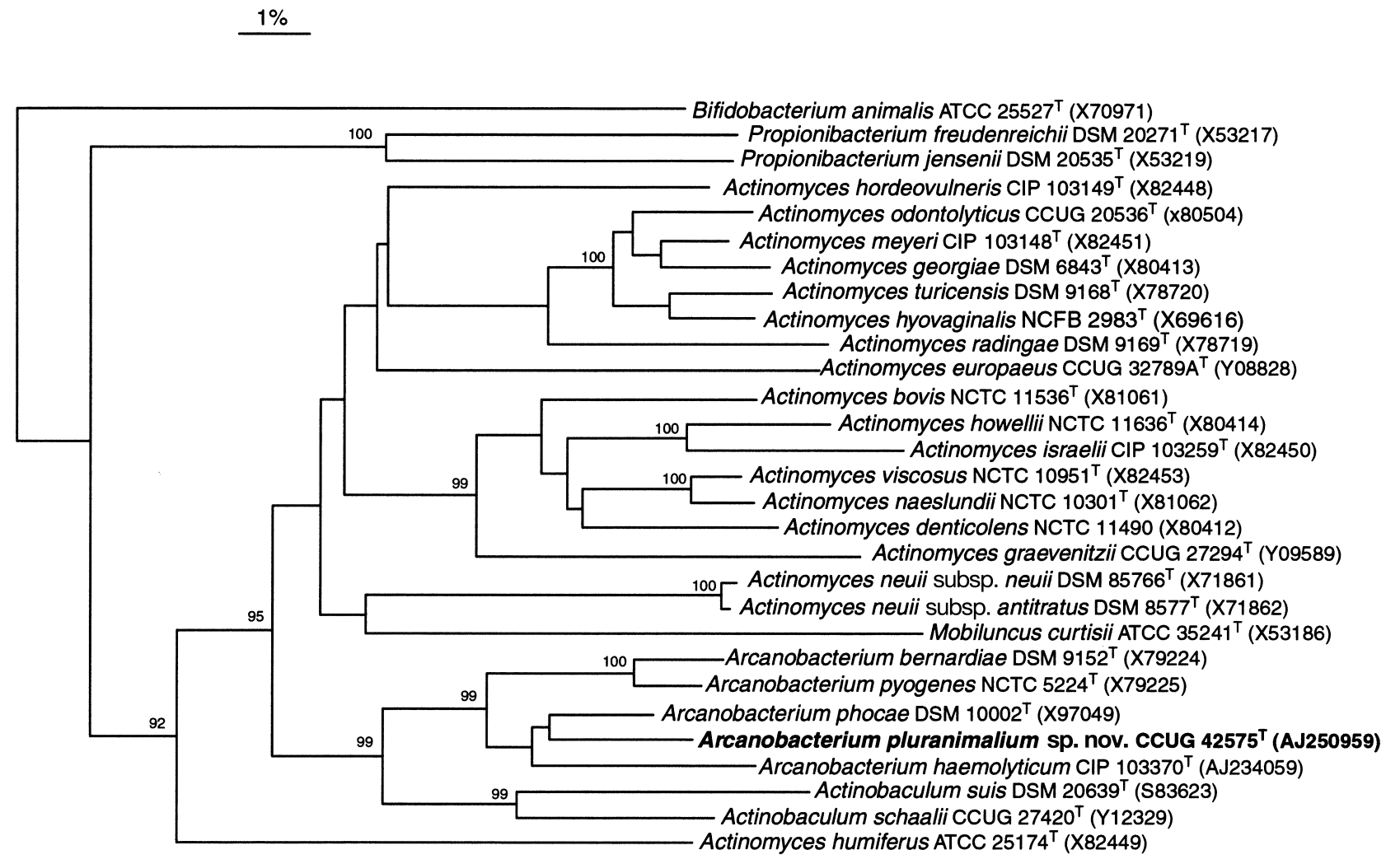

Fig. 2. Unrooted tree showing the phylogenetic relationships of Arcanobacterium pluranimalium sp. nov. and some other high-G + C-content Gram-positive bacteria. The tree, constructed using the neighbour-joining method, was based on a comparison of approximately $1327 \mathrm{nt}$. Bootstrap values, expressed as a percentage of 500 replications, are given at branching points. Scale bar, $1 \%$ sequence divergence.

phosphatase, $\alpha$-glucosidase, $\beta$-glucosidase, $\alpha$-galactosidase, $\beta$-galactosidase, $\beta$-galacturonidase, $N$-acetyl- $\beta$ glucosamine, $\beta$-mannosidase and urease. Variable reactions were observed for pyrazinamidase and glycyl tryptophan arylamidase. Both isolates hydrolysed aesculin (weak reaction), gelatin and hippurate and gave a negative Voges-Proskauer test. They did not reduce nitrate to nitrite. The cellular morphology and biochemical reactions of the isolates were consistent with their assignment to the genus Arcanobacterium, although they did not appear to correspond to any described species of the genus. An examination of the cell wall murein of strain CCUG $42575^{\mathrm{T}}$ revealed a murein structure L-Lys-Lys-D-Glu (type A5 $\alpha$ ) (nomenclature of Schleifer \& Kandler, 1972) consistent with Arcanobacterium haemolyticum, the type species of the genus. To our knowledge, the only other described species containing this murein type corresponds to Actinomyces europeaus and Actinomyces neuii (Funke et al., 1997). The $\mathrm{G}+\mathrm{C}$ content of strain CCUG $42575^{\mathrm{T}}$ was $57 \mathrm{~mol} \%$. This value is within the published range (approx. 48-66 mol \%) for the genus Arcanobacterium (Collins et al., 1982; Funke et al., 1995).

A numerical analysis of the whole-cell protein patterns of the two strains of Arcanobacterium pluranimalium together with the reference strains of Arcanobacterium is shown in Fig. 1. The two isolates clustered together and formed a distinct group with a correlation level of $85 \%$. Actinomyces neuii subsp. antitratus and subsp. neuii were the nearest species to the unknown isolates on PAGE analysis, joining the latter group at a correlation of about $55 \%$ (Fig. 1). The PAGE results confirmed that the two unidentified strains represent a phenotypically homogeneous group of organisms and indicated that they are distinct from all Arcanobacterium and Actinomyces species described to date.

To ascertain the phylogenetic relationships of the unknown isolates, their $16 \mathrm{~S}$ rRNA genes were sequenced and subjected to a comparative analysis. The almost complete gene sequences ( $>1500 \mathrm{nt}$ ) of the two strains were determined and pairwise analysis showed these to be identical (100\% sequence similarity in 1420 bases compared). Sequence database searches confirmed that the unknown bacterium was most closely related to species of the genus Arcanobacterium (range 93.9-96.5\%). Highest sequence relatedness was shown with Arcanobacterium phocae (96.5\% similarity). The results of neighbour-joining analysis are shown in Fig. 2 and confirmed the association of the unknown clinical bacterium (as exemplified by strain CCUG $42575^{\mathrm{T}}$ ) with the genus Arcanobacterium. 
Table 1. Tests useful for identifying Arcanobacterium pluranimalium

+ , Positive; - , negative; $+\mathrm{w}$, weak positive; $-(+)$, a few strains positive; $+(-)$, a few strains negative; v, variable.

\begin{tabular}{|c|c|c|c|c|c|}
\hline Test & $\begin{array}{c}\text { Arcanobacterium } \\
\text { bernardiae }\end{array}$ & $\begin{array}{c}\text { Arcanobacterium } \\
\text { haemolyticum }\end{array}$ & $\begin{array}{c}\text { Arcanobacterium } \\
\text { pluranimalium }\end{array}$ & $\begin{array}{c}\text { Arcanobacterium } \\
\text { phocae }\end{array}$ & $\begin{array}{c}\text { Actinomyces } \\
\text { pyogenes }\end{array}$ \\
\hline \multicolumn{6}{|l|}{ Acid from: } \\
\hline Lactose & - & + & - & $\mathrm{v}$ & + \\
\hline Glycogen & + & - & - & + & $\mathrm{V}$ \\
\hline D-Ribose & + & - & + & + & + \\
\hline D-Xylose & - & - & - & $\mathrm{v}$ & + \\
\hline \multicolumn{6}{|l|}{ Hydrolysis of: } \\
\hline Aesculin & - & - & $+\mathrm{w}$ & - & - \\
\hline Gelatin & - & - & + & - & + \\
\hline Hippurate & - & - & + & - & $+(-)$ \\
\hline \multicolumn{6}{|l|}{ Production of: } \\
\hline Catalase & - & $-(+)$ & + & $\mathrm{v}$ & $-(+)$ \\
\hline$\alpha$-Galactosidase & - & - & - & $+\mathrm{w}$ & - \\
\hline$\beta$-Galactosidase & - & - & - & + & + \\
\hline$\beta$-Galacturonidase & - & + & - & + & + \\
\hline$\beta$-Glucuronidase & - & $-(+)$ & + & - & + \\
\hline Pyroglutamic acid arylamidase & - & $-(+)$ & + & - & - \\
\hline
\end{tabular}

It is apparent from both phylogenetic and phenotypic evidence that the two unidentified isolates recovered from a dead harbour seal and a dead sallow deer represent a hitherto unknown Arcanobacterium species. Both sequence divergence and treeing analysis show that the unidentified bacterium represents a distinct subline within the genus Arcanobacterium. The nearest relative of the unknown organisms corresponds to Arcanobacterium phocae, a species recovered from clinical specimens of common seals and grey seals (Pascual et al., 1997). Although there is no precise correlation between the degree of $16 \mathrm{~S}$ rRNA sequence divergence and species delineation, it is generally recognized that divergence values of $3 \%$ or more are significant (Stackebrandt \& Goebel, 1994). The observed $3.5 \%$ divergence between the unknown bacterium and Arcanobacterium phocae, and even greater divergence values with other Arcanobacterium species, is consistent with separate species status. The separateness of the unknown bacterium was also demonstrated by PAGE analysis of whole-cell proteins and biochemical profiling. In particular, the unknown bacterium can be readily distinguished from all currently described Arcanobacterium species by the traits shown in Table 1. Therefore, based on both phylogenetic and phenotypic evidence, it is proposed that the unidentified isolates be classified in a new species of the genus Arcanobacterium, Arcanobacterium pluranimalium.

\section{Description of Arcanobacterium pluranimalium sp.} nov.

Arcanobacterium pluranimalium (plur.an.im.al'i.um. L. adj. pluris many; L. n. gen. pl. animalium from animals; M.L. gen. n. pluranimalium from many animals).
Cells are straight to slightly curved, non-branching, slender rods which stain Gram-positive, are non acidfast and non-motile. Facultatively anaerobic and catalase-positive. Using API systems, acid is produced from D-glucose and D-ribose, but not from D-arabitol, L-arabinose, cyclodextrin, glycogen, pullulan, sorbitol, tagatose, mannitol, melibiose, melezitose, lactose, Draffinose, sucrose, trehalose or D-xylose. Maltose is variable. Alanine phenylalanine proline arylamidase, pyroglutamic acid arylamidase and $\beta$-glucuronidase are detected, but not arginine dihydrolase, alkaline phosphatase, $\alpha$-glucosidase, $\beta$-glucosidase, $\alpha$-galactosidase, $\beta$-galactosidase, $\beta$-galacturonidase, $N$-acetyl$\beta$-glucosamine, $\beta$-mannosidase or urease. Pyrazinamidase and glycyl tryptophan arylamidase may or may not be detected. Aesculin (weak reaction), gelatin and hippurate are hydrolysed. Acetoin is not produced. Nitrate is not reduced to nitrite. The cell wall contains a murein structure L-Lys-Lys-D-Glu (type A $5 \alpha$ ). Isolated from a dead harbour porpoise and a dead sallow deer. Habitat is not known. The type strain is CCUG $42575^{\mathrm{T}}$. The $\mathrm{G}+\mathrm{C}$ content of DNA of the type strain is $57 \mathrm{~mol} \%$.

\section{ACKNOWLEDGEMENTS}

We are grateful to Lena Dahl for performing PAGE analyses. Thanks are also given to Hans Trüper for suggesting the species epithet and the support of A. Patterson and R. Reid of SAC Veterinary Science Division is acknowledged. This work forms part of an ongoing study of Scottish Strandings and was supported in part by the UK Department of the Environment, Transport and the Regions as part of its coordinated programme of research on the North Sea. 


\section{REFERENCES}

Collins, M. D., Jones, D. \& Schofield, G. M. (1982). Reclassification of 'Corynebacterium haemolyticum' (MacLean, Liebow \& Rosenberg) in the genus Arcanobacterium gen. nov. as Arcanobacterium haemolyticum nom. rev., comb. nov. J Gen Microbiol 128, 1279-1281.

Devereux, J., Haeberli, P. \& Smithies, O. (1984). A comprehensive set of sequence analysis programs for the VAX. Nucleic Acids Res 12, 387-395.

Felsenstein, J. (1989). PHYLIP - phylogeny inference package (version 3.2). Cladistics 5, 164-166.

Funke, G., Pascual Ramos, C., Fernandez-Garayzabal, J., Weiss, N. \& Collins, M. D. (1995). Description of human-derived Centers for Disease Control coryneform group 2 bacteria as Actinomyces bernardiae sp. nov. Int J Syst Bacteriol 45, 57-60.

Funke, G., Alvarez, N., Pascual, C., Falsen, E., Akervall, E., Sabbe, L., Schouls, L., Weiss, N. \& Collins, M. D. (1997). Actinomyces europaeus sp. nov., isolated from human clinical specimens. Int J Syst Bacteriol 47, 687-692.

Pascual, C., Foster, G. \& Collins, M. D. (1997). Phylogenetic analysis of the genus Actinomyces based on 16S rRNA gene sequences: description of Arcanobacterium phocae sp. nov., Arcanobacterium bernardiae comb. nov., and Arcanobacterium pyogenes comb. nov. Int $J$ Syst Bacteriol 47, 46-53.

Pot, B., Vandamme, P. \& Kersters, K. (1994). Analysis of electrophoretic whole-organism protein fingerprints. In Modern Microbial Methods (Chemical Methods in Prokaryotic Systematics Series), pp. 493-521. Edited by M. Goodfellow \& A. G. O’Donnell. Chichester: Wiley.

Schleifer, K. H. \& Kandler, O. (1972). Peptidoglycan types of bacterial cells walls and their taxonomic implications. Bacteriol Rev 36, 407-477.

Stackebrandt, E. \& Goebel, B. M. (1994). Taxonomic note: a place for DNA-DNA reassociation and 16S rRNA sequence analysis in the present species definition in bacteriology. Int $J$ Syst Bacteriol 44, 846-849.

Vandamme, P., Torck, U., Falsen, E., Pot, B., Goossens, H. \& Kersters, K. (1998). Whole-cell protein electrophoretic analysis of viridans Streptococcus mitis biovars. Int J Syst Bacteriol 48, $117-125$. 